\title{
11. Conclusions: lessons, limitations and way forward
}

\author{
Jakob Edler, Charles Edquist, \\ Nicholas S. Vonortas and Jon Mikel \\ Zabala-Iturriagagoitia
}

As stated in the Introduction, this book aims to provide a wellrounded understanding of the key determinants in implementing effective public procurement initiatives to achieve innovative outputs. The book provides both case studies and conceptual contributions that help to extend the frontiers of our understanding in areas where there are still significant gaps. The contributions are deliberately broad and diverse to show the range of issues that still need better understanding and reflection regarding public procurement for innovation (PPI). Out of this range of issues we may extract a set of key messages and implications for further research, procurement practice and innovation policy.

The contributions remind us of an important distinction between, on the one hand, the policy of using public procurement to spur innovation as part of demand-side policies, and on the other hand, the public procurement practice that aims to solve a specific societal problem or improve a certain public service and in doing so asks for (and commits to buy) something new. The two are often linked, but PPI as a policy instrument cannot be thought of without the procurement practice on the ground. PPI as a demand-side innovation policy instrument is a systematic attempt by authoritative public bodies to mobilize the purchasing power of the state (national, regional) for innovation policy goals. PPI as practice on the ground has a different logic; the innovation is a necessary means for achieving some other goals not necessarily related to innovation policy.

This distinction has certain implications: (1) isolated PPI practice on the ground cannot be assessed against the innovation policy criteria of PPI as a policy instrument; (2) policy learning 
needs to be derived from the former to the latter; and (3) the remit of PPI should be broadly understood. PPI can constitute a type of policy in its own right, with its own frameworks and innovation-related goals and even its own specialized agencies. However, PPI can also be understood as a policy instrument that seeks to uplift the capabilities within procuring bodies, and improve the framework conditions to enable the general public procurement practice to ask for and buy more innovations. The book contains illuminating examples of both cases with important overall policy lessons.

\section{LESSONS FROM PPI AS AN INNOVATION POLICY TOOL}

Four of the chapters clearly deal with PPI as a policy tool. In the country case of the USA, there is a Federal Framework that in some areas is designed to use public procurement as a policy instrument to spur innovation. As Vonortas has shown in Chapter 6, a similar basic framework across different policy areas at the federal level has very different results. For example, the stated PPI policy in the case of the environment works better than in other areas. The key lessons that can be derived from the US example are, among others, the idea of innovation generation being framed as an integral element to pursue the 'social cause' of environmental protection, and the PPI policy being designed through a bundle of measures, from regulation to 'policing' of practice, as well as guidance and information.

Similarly, the Chinese example of the procurement of electrical vehicles by Li et al. (Chapter 7) shows how PPI is used to improve the further development of those vehicles and accelerate their dissemination. These are classical innovation policy aims, and the means used are public procurement mechanisms. However, this example is reminiscent of the inbuilt tensions when public procurement is designed as an innovation policy tool first and foremost geared towards the economic effect of the innovation, rather than the societal and public service effect. In these cases, policy makers are seeking maximum innovation return within their own constituencies at the expense of maximum benefit for public service.

The chapter shows that while individual procurement processes within the scheme have worked, and commercialization 
of e-vehicles has been fostered, the overall economic benefit has been far more limited than expected. The reasons are important general lessons for PPI policy: first, protectionism by the regional buying bodies suppressed the broader competition that would lead to better solutions across the country. Second, as the national level did not have the leeway to control implementation, the attempt to govern through quantitative targets failed. This is a major challenge of PPI as policy; it is often designed at a higher, political level, while the implementation happens at lower levels, where interests are more local, capabilities more limited and additional support and incentives, such as cofunding and educating of procuring bodies (the demand side), are essential.

The forward commitment procurement $(\mathrm{FCP})$ scheme introduced by van Meerveld et al. in Chapter 5 offers a similar lesson to the Chinese example. FCP has been designed as tool offering procuring bodies a means to reduce risk and improve interaction and expectation management. Here, we have a very simple but powerful first lesson to learn: it is possible to design mechanisms that tackle some of the core, fundamental challenges of procurement practice, that is, the management of risk and expectations, giving suppliers a firm and reliable goal to work towards, as there is a purchase at the end of a first-stage development process. However, a second lesson, linking to the Chinese example, is hidden: the instrument has not really been rolled out; we observe again a centrally designed instrument that is geared towards innovation, and the lack of uptake of this instrument across procuring bodies. PPI policy that should work across constituencies, not only for dedicated individual ministries or organizations, needs to ensure that the broader conditions are met for public bodies to take advantage of the instrument that is designed for them at a central level.

The case of Petrobas (Ribeiro and Furtado, Chapter 10) is a final example of PPI as a deliberate innovation policy. It offers a similar lesson, but with supply-side implications. Here the procurement power and a specific design of the procurement process of a state-owned company are used in order to uplift the technological competencies of incumbent firms. Again, this is a core innovation policy goal, which is linked to a whole range of further policy goals. The initiative largely failed in this innovation goal, as the incumbent local firms in supply chains did not have the learning capacity in place. Mobilizing firms into 
innovation procurement initiatives through the supply chain, and hoping for an innovation uplift, did not work. Firms need a basic level of innovation capacity in the first place to benefit from innovation procurement. The policy lesson here is clear: if PPI is to uplift the innovation capacities of firms, this uplift itself needs to be prepared and supported with appropriate supply side measures.

\section{POLICY LESSONS FROM PPI PRACTICE TO ACHIEVE ORGANIZATIONAL AND POLICY IMPROVEMENT}

Two examples are devoid of deliberate innovation policy initiatives, but deliver important lessons for PPI policy. The e-government case in Greece (Caloghirou et al., Chapter 8) and the recycled paper case (Yeow et al.) are first and foremost initiatives to improve public service provision. Part of the delivery of this improvement is the procurement of new goods and/or services. In both cases, the basis for the procurement process is not a classical innovation policy rationale, and the innovation as such is not the success metric here: the efficient and effective provision of the service is. Of course, trying to understand what works and what does not work when procuring innovation, we look at the innovation effects (or the lack of them) and try to derive important lessons for a more general support of public procurement of innovation.

The e-government case offers us an insight into a mechanism which seeks to develop an innovative solution at one entry point and then roll out this solution more broadly. The initial procurement is the test bed or a systemic change. The case reconfirms the importance of champions, of lasting relationships between suppliers and demanders. The case demonstrates how technological lock-in can be avoided when buying highly innovative systems through open source and open standards. However, it also illuminates the limits of central initiatives that are to be rolled out, as the lack of capabilities and user engagement, as well as resistance to intra-organizational change, are limiting factors at lower levels, aggravated by poor supply chain involvement and management at local level.

The closed loop recycled paper case teaches us the importance of problem pressure for PPI practices to be initiated and to actually work, up to a point where the risk of non-innovation 
is perceived to be higher than the risk of failing with an innovation. While the case also focuses on the importance of leadership, it reminds us of the tension of lasting relationships between producers and the buying organizations, both enabling (joint learning) and stifling innovation (through lock-in, lack of competition).

\section{POLICY LESSONS FROM CONTRIBUTIONS FOCUSED ON BARRIERS IN PROCUREMENT PRACTICE MORE BROADLY}

Three contributions in the book do not take concrete procurement cases or countries into focus, but specific challenges. Those challenges must be at the heart of PPI policy. In their survey of suppliers, Edler et al. (Chapter 2) show that, in principle, there are practices and processes out there that deliver innovation across the public sector, but public bodies are not able and/ or willing to apply them. A core challenge that is at the root of many of those organizational practices is risk aversion. In this sense, Edler et al. (Chapter 4) make a first attempt to understand risk conceptually and call for a differentiation of risk for different actors and in different stages of a procurement process. Only if we understand those risks in detail can we devise policy strategies within PPI policies that manage risk in a productive way. In turn, Valovirta (Chapter 3) makes a first step in developing concrete management requirements based on the understanding of multiple challenges for procuring organizations, which we may read as a manual for procuring organizations.

These, and several of the application-relevant observations scattered across the chapters, treating specific procurement cases or country approaches, tie in quite well with the challenges stressed in the introductory chapter section on the operationalization of public procurement for innovation. Three of those challenges stand out as needing attention:

1. Translation of the identified societal goal of public procurement into functional requirements. Long experience points to the utility of 'functional procurement': the procuring agency formulates requirements in functional terms rather than in product terms, thus allowing the prospective suppliers to use their creativity and innovativeness to meet the desired 
functionality. A prerequisite for success is the early engagement of stakeholders and expert advisory bodies. Important threats here originate in 'special interests', including the interests of politically influential organizations married to particular technological solutions (trajectories) and/or the interests of influential social groups.

2. Translation of the functional specification into technical requirements. While it is prudent to let prospective bidders translate the desired functionalities into technical specifications, such practice is antithetical to the incentives of purchasing managers bent on minimizing risk exposure. Risk reduction can be achieved by either procuring off-the-shelf products - thus also achieving short-term cost reduction objectives - or by detailing technical specifications. None of these is harmonious with innovation. In order to incentivize public employees to take on more risk, elected officials must offer protection by assuming the responsibility associated with spending taxpayers' money.

3. Delivery process. This stage of procurement encompasses product development, production and final delivery to the purchasing agency. While time and cost overruns are not unusual in public procurement, they become more acute in PPI due to the uncertainties of the targeted programmes in radical, game-changing technologies. The inevitable interference of the political system to accommodate the evolving, and occasionally contrasting, interests of stakeholders also exacerbates the problem.

We do hope that the concepts, insights and lessons presented in this book are instrumental in supporting policy makers and procurement practitioners in their effort to better use the public purse to initiate and support innovation for economic growth and, more broadly, societal welfare. This book fills gaps, but also opens new avenues. We can finish with some bold but simple messages for policy and academia:

1. PPI as an innovation policy instrument must be based on a good understanding of the challenges down at the organizational level and the different interests at different policy levels. While large innovation procurement initiatives may make a difference, the real difference is made if the whole innovation system is uplifted, if all levels understand the 
issues required, and if the public sector puts emphasis on and opens debate with multiple stakeholders in order to deal with them. Learning from PPI practice, as shown in this book, is a first step in this direction.

2. PPI as innovation policy must be based on a good understanding of the need for absorptive and innovative capacity, and thus develop systemic approaches. PPI must be embedded into a range of policy instruments, from both demand and supply sides, that provide the requirements for it to improve its effectiveness in mitigating social demands or improving agency needs.

3. PPI policy must be able to ensure that the challenges identified at the practice level can be overcome by actors at all levels: by those implementing procurement initiatives, by those supplying them and by those benefiting from them. Tackling societal challenges in isolated large-scale PPI initiatives will not deliver the breadth needed. Therefore, PPI must be understood not as an ensemble of grand initiatives, but as a systematic roll-out of schemes, instruments and framework conditions that overcome those challenges across the system. This would ensure that PPI practice in general turns towards an (implicit) tool for PPI and innovation policy.

The academic interest in PPI policy will continue, and must continue. While the innovation policy community certainly has knowledge and experience of policy instruments and challenges, more knowledge is needed about the organizational conditions that make some organizations less vulnerable than others. This book has provided a clear set of managerial implications, but a long bridge still needs to be crossed if the efficiency and the effectiveness of the public sector are to be further improved.

The interest in demand-side policy measures in general has gained momentum in the last few years, and so have particular instruments such as PPI. However, the evaluation of demandside innovation policies is still in its infancy. Thus, contributions from both the policy evaluation community and the innovation policy community are needed in order to be able to develop comprehensive frameworks and methodologies, and to define the required indicators that may feed them. Only in this way will it be possible to achieve a co-evolution between the development of the innovation policy community and its related evaluation practice. 
